\title{
VIOLACIÓN DEL DERECHO INTERNACIONAL HUMANITARIO POR PARTE DEL ESTADO COLOMBIANO
}

\author{
Yanitza GIRALDA RESTREPO*
}

RESUMEN: El Estado colombiano se encuentra en un conflicto desde hace más de cuarenta años, es uno de los más antiguos de Latinoamérica. A causa de esto, se ha generado un desplazamiento interno. Los civiles que se encuentran en medio de los ataques, son obligados a dejarlo todo para poder salvar sus vidas.

ABSTRACT: The Colombian State is in a conflict for more than forty years, it is one of the most ancient of Latin America. Because of this, an internal displacement has been generated. The civil ones who think in the middle of the assaults are forced to leave everything to be able to save his lives.

RÉSUMÉ: L'État Colombienne est trouvé dans un conflit il y a plus de quarante ans, il est un de plus antique dans l'Amérique Latin. A cause de ça, un déplacement interne a était produit. Les civils qui se trouve au milieu des attaques sont obliges á quitte tout pour sauver ses vies.

* Estudiante del Doctorado en Derecho General, en la Universidad Carlos III de Madrid. 
SumARIO: I. Introducción II. Antecedentes en Colombia. III. Desplazamiento interno y derechos humanos. IV. La comunidad internacional y la ayuda humanitaria. V. Conclusiones.

\section{INTRODUCCIÓN}

El conflicto armado que vive Colombia desde hace muchos años ha causado el desplazamiento interno de su población. Los éxodos forzados han sido un instrumento empleado por los diferentes actores del conflicto con el propósito de obtener el control sobre la tierra, los recursos, la población; bien sea con fines económicos, o simplemente estratégicos. A causa de la violencia que se vive en distintas regiones del país, muchos colombianos han perdido su centro: el de sus afectos, querencias, tierra y hogar. Se encuentran desplazados y errantes, perseguidos por la violencia, indefinidos ante un horizonte que se aleja cada día más. ${ }^{1}$

El desplazamiento interno en Colombia y en el mundo por causas ligadas al conflicto armado no es cosa nueva, pero tal fenómeno alcanza cifras críticas. ${ }^{2}$ De tal manera, podemos decir que el desplazamiento forzado $^{3}$ constituye una herramienta efectiva para los intereses políticos y a su vez la consolidación de proyectos económicos, que tienen como estrategia de guerra los diferentes actores armados y grupos de narcotraficantes en desarrollo de coaliciones, con el objetivo de lograr la expansión del control social y político en todo el territorio nacional.

Teniendo en cuenta lo anterior, el objeto de este trabajo es mostrar la violación del derecho internacional humanitario y la responsabilidad internacional por parte del Estado colombiano, en tanto que incumple normas de carácter internacional, ${ }^{4}$ que lo obligan a respetar los derechos hu-

1 Strouss de Samper, Jacquin, Los desplazados. Esa Colombia que no podemos ignorar, Santa Fe de Bogotá, Imprenta Nacional, 1997, p. 7.

2 UNCHR, Les Réfugiés das le monde 1997-1998, París, La Découverte, 1997, p. 105.

3 Artículo 284-A. Ley 589 del 6 de junio de 2000, "Por la cual se expide el Código Penal". En ella se tipifica el genocidio, la desaparición forzada, el desplazamiento forzado y la tortura; y se dictan otras disposiciones, véase Diario Oficial del 7 de julio de 2000, núm. 44.073.

4 Incumple tratados que han sido ratificados por este, tales como las violaciones graves del artículo 3o. común a los Cuatro Convenios de Ginebra del 12 de agosto de 1949 (artículo 8o., apartado 2, inciso c, e). Estatuto de la Corte Penal Internacional que 
manos. $\mathrm{Y}$ es que no debemos seguir con el paradigma tradicional de soberanía - respeto a la autonomía absoluta dentro de su territoriopues, a partir de que vivimos en un mundo de derechos humanos, esto no puede seguir más en boga. De tal suerte, éstos tienen autonomía para actuar en su territorio siempre y cuando no violen derechos humanos de ninguna persona, extranjera o nacional.

En este sentido, me centraré en un problema actual y de gran trascendencia nacional, como internacional: el fenómeno del desplazamiento interno colombiano. Por otra parte, pretendo explicar cuáles son las implicaciones que pueden tener dentro de la sociedad las violaciones masivas de los derechos humanos hacia las mujeres, niños y personas especialmente vulnerables y protegidas dentro del derecho internacional humanitario, como también la responsabilidad penal en que incurren los diferentes grupos que provocan el desplazamiento interno de la población.

Finalmente, vale la pena advertir que las violaciones a los derechos humanos perpetradas por los grupos armados al margen de la ley y la situación de violencia en la que ha vivido sumido el país, han impuesto grandes retos y dificultades a las labores de prevención, protección, garantía y difusión de los derechos humanos adelantadas por el Estado colombiano. Ello lo ha llevado a reforzar sus acciones y estrategias hacia un enfoque preventivo, fortalecer su estrategia de lucha contra la impunidad, obtener una reparación adecuada para las víctimas de la violencia, impulsar medidas efectivas de aplicación del derecho internacional humanitario y a racionalizar el funcionamiento de sus instituciones.

\section{ANTECEDENTES EN COLOMBIA}

Se estima que a finales de los años cuarenta se registró una gran escalada de violencia la cual tuvo sus orígenes en la problemática social, como en las luchas de las elites. El 9 de abril de 1948 Jorge Eliécer Gaitán, abogado cooptado por el partido liberal con ideas socialistas, fue asesinado en el centro de Bogotá. ${ }^{5}$ Él tenía la representación de las espe-

fue ratificado por Colombia el 15 de agosto de 2002 (artículo 7o., crímenes de lesa humanidad, y artículo 8o., crímenes de guerra).

5 Waldmann, Peter et al. (comp.), Sociedad en guerra civil. Conflictos violentos de Europa y América Latina, Barcelona, Paidós, 1999, p. 264. 
ranzas de la clase media urbana, y había logrado que se acercaran al partido liberal, personas de la clase obrera.

Posterior a esto, se generó una ola de violencia contra todos los símbolos de poder iniciada por comerciantes, artesanos y población desplazada del campo. A ésta escalada de violencia se le denominó "el Bogotazo", la cual dio inicio a un periodo de actos violentos que se fueron propagando en las regiones rurales y entraron a formar parte de la historia con el nombre de "la Violencia". Se estima que cerca de trescientas mil personas murieron a causa del enfrentamiento entre conservadores y liberales, y que otros dos millones de individuos fueron despojados de sus tierras. ${ }^{6}$

Éste conflicto se presentaba de igual forma en las ciudades y zonas rurales en la cual ambos luchaban por un mismo fin, la igualdad social; sin embargo, la confrontación permanente era una muestra cada vez más clara de un conflicto entre partidos, de manera concreta entre el Partido Liberal y el Partido Conservador. Esto se debía a la carencia de medios económicos de las personas más necesitadas que los hacia depender de otras fuentes de financiación para continuar con la ya iniciada guerra de guerrillas.

Los seguidores del Partido Liberal se alejaron de la política oficial y lucharon en las zonas cafeteras y de colonización al lado de los campesinos. El Poder Judicial, el Ejército y la Policía dejaron de ser neutrales, ejerciendo un régimen absolutamente totalitario. Los conservadores enviaban a los pueblos liberales a los policías reclutados en lugares conservadores; financiaban asesinos para expulsar a los ocupantes y campesinos de terrenos que reclamaban como suyos. A su vez, los liberales armados intentaban mantener grandes territorios bajo su control utilizando de manera más frecuente los métodos de la guerrilla, algo que se extendió y generó la delincuencia común de bandoleros, soldados y asesinos.

A causa de esto, y después del golpe de Estado perpetrado por el general Gustavo Rojas Pinilla en 1953, el cual gozó en su momento del apoyo de las elites liberales, se instituye el Frente Nacional (1954-1958), la alternancia del poder. ${ }^{7} \mathrm{Si}$ bien es cierto que atenuó radicalmente la

6 Cfr. UNCHR, op. cit., nota 2, p. 110.

7 Por medio de este acuerdo, los partidos Liberal y Conservador se alternarían en la presidencia por periodos de cuatro años, distribuyéndose por igual, la formación de los 
violencia bipartidista, igualmente significó la exclusión de otros sectores que no habían tenido un verdadero protagonismo. A pesar de este esfuerzo de liderazgo estatal con la creación del sistema del Frente Nacional y los resultados positivos a nivel económico, surgió un movimiento insurreccional el cual con sus diferentes vertientes y manifestaciones dura hasta nuestros días. La exclusión de los terceros grupos de una participación activa, la falta de oportunidades, el centralismo administrativo que se tuvo en el periodo del Frente Nacional, son algunas de las causas relevantes para el nacimiento de la guerrilla.

Durante los años sesenta, ${ }^{8}$ y hasta principios de los noventa, el Estado colombiano adoptó medidas cada vez más represivas dentro del marco de estados de excepción para contrarrestar el avance de la guerrilla; a causa de ello, ésta se multiplicó en movimientos, frentes, unidades y hombres. En el conflicto entre la guerrilla y los militares, surge un tercer actor: los paramilitares, que en el caso colombiano pretenden suplir la carencia de fuerza (policía miliar) cuyo único titular debe ser el Estado. ${ }^{9}$ Sin embargo, guerrilleros y paramilitares son considerados como movimientos al margen de la ley, por tanto, deben ser neutralizados por el Estado, mediante el diálogo entre los actores del conflicto.

Esta violencia entre los grupos armados ha generado el aumento exponencial sobre el número de desplazados en los últimos años. La mayoría de estas personas son campesinos que pertenecen a las poblaciones negras e indígenas presentes en medio del conflicto. Como estrategia o táctica, aquellas personas resultan ser sus víctimas directas obligándolos a huir a otras partes del país y atentando contra sus vidas al considerarlas colaboradoras del enemigo. ${ }^{10}$ A consecuencia de esto, huyen hacia el ex-

dos grupos, todos los cargos públicos. Este acuerdo sería incorporado en la Constitución, mediante plebiscito el 1o. de diciembre de 1957.

8 Kirk, Robin, More Terrible Than Deaths. Massacres, Drugs and America's War in Colombian, Nueva York, Public Affaire, 2003, pp. 41-65.

9 Al respecto, véase Andreu-Guman, Federico, "Derechos humanos en Colombia: tres décadas de violaciones e impunidad", en varios autores, Colombia ante los retos del siglo XXI. Desarrollo democracia y paz, Universidad de Salamanca, 2001, p. 252.

10 El artículo 159 del Código Penal tipifica dentro de los delitos contra las personas y bienes protegidos por el DIH (título II), el desplazamiento forzado de la siguiente manera: "Deportación, expulsión, traslado o desplazamiento forzado de población civil. El que, con ocasión y en desarrollo de conflicto armado y sin que medie justificación militar, deporte, expulse, traslade o desplace forzadamente de su sitio de asentamiento a la población civil, incurrirá en prisión de diez (10) a veinte (20) años, multa de mil $(1,000)$ 
terior de las zonas rurales siendo lo más próximo pueblos cercanos, ciudades y generando un grave problema al llegar a crear hogares improvisados que a su vez originan los llamados cordones de miseria (invasiones). ${ }^{11}$

Esta situación presente en el Estado colombiano no se desarrolla en medio de un vacío jurídico, por el contrario, se encuentra tipificado en el Código Penal en el evento que se presente un conflicto armado bajo el título II el cual hace referencia a "delitos contra personas y bienes protegidos por el derecho internacional humanitario" (artículo 159) y en "delitos contra la libertad individual y otras garantías" (artículo 180).

\section{DESPLAZAMIENTO INTERNO Y DERECHOS HUMANOS}

\section{Los derechos humanos}

Las violaciones de manera general de los derechos humanos y del derecho internacional humanitario presentes en Colombia son cometidas por diferentes actores del conflicto tales como guerrillas, grupos paramilitares y fuerzas armadas. Éstos son los responsables de las masacres, asesinatos, secuestros y otras violaciones graves de los derechos humanos que son considerados crímenes de guerra o crímenes contra la humanidad. ${ }^{12}$ No obstante, el Estado incurre en responsabilidad internacional

a dos mil $(2,000)$ salarios mínimos legales mensuales vigentes, e inhabilitación para el ejercicio de derechos y funciones públicas de diez (10) a veinte (20) años".

11 Según la Consultoría para los Derechos Humanos y el Desplazamiento (CODHES), entre el 10. de julio y el 30 de septiembre de 2005, alrededor de 99,338 personas, que integran 19,868 hogares, fueron desplazadas de sus sitios habituales de vivienda o trabajo por hechos de violencia e inseguridad asociados al escalamiento del conflicto armado interno, lo que significa un incremento del $32 \%$ con relación al mismo periodo de 2004. Es decir, un promedio de 1,080 personas fueron desplazadas cada día de este trimestre, bien sea por acciones directas de las partes contendientes contra la población civil o por los efectos indiscriminados que provoca una confrontación armada en la que prevalecen las estrategias militares sobre los derechos de la gente. Estas personas llegaron a 566 municipios de 31 departamentos del país, lo que marca la continuidad de la crisis humanitaria en casi todo el territorio nacional. En estos tres meses se registró el desplazamiento masivo de 8,612 personas que se movilizaron en 30 éxodos, mientras que otras 8,493 se asentaron en municipios fronterizos de Colombia con Ecuador, Venezuela y Panamá, http://www.Codhes.org.

12 Crímenes contra la humanidad significa cualquiera de los actos cometidos por parte de un ataque generalizado o sistemático y dirigido en contra de cualquier población 
por los hechos ocurridos a los individuos que hacen parte de su territorio, ya sean éstos nacionales o extranjeros; a su vez, responde por las acciones $\mathrm{u}$ omisiones las cuales generan un hecho internacionalmente ilícito dentro o fuera de su territorio. ${ }^{13}$

La CDHNU14 (en adelante la Comisión) "observó en 2004 que los grupos armados ilegales cometieron la inmensa mayoría de los atentados contra el derecho internacional humanitario y de los actos delictivos". Condenó el hecho que ningún actor armado respetó el derecho internacional humanitario, especialmente los principios de distinción, proporcionalidad, limitación e inmunidad de la población civil y la continuación de agresiones indiscriminadas, homicidios, masacres, toma de rehenes, secuestros, desplazamiento forzado, violencia contra mujeres, niños y actos de terrorismo. ${ }^{15}$

La Declaración expresó la preocupación de la Comisión por los constantes actos de violencia contra niños, niñas y mujeres, ${ }^{16}$ especialmente situaciones de violencia sexual. Además, se refirió al reclutamiento de menores por parte de los grupos armados ilegales; señaló que es

civil, teniendo conocimiento del ataque. Sobre este tema se puede consultar el Estatuto de Roma de la Corte Penal Internacional en el artículo 7.2.a. Entre otros autores: Ambos, Kai, Temas de derecho penal internacional y europeo, Madrid, Marcial Pons, 2006, pp. 167-170; Peco Yeste, Miguel y Peral Fernández, Luis, El conflicto de Colombia, Madrid, Instituto de Estudios Internacionales y Europeos "Francisco de Vitoria", 2005, p. 69; González Campos, Julio D. et al., Legislación básica de derecho internacional público, 3a. ed., Madrid, Tecnos, 2003, p. 165.

13 El reconocimiento y defensa de los derechos humanos ha evolucionado con el tiempo, experimentando un amplio desarrollo por vía convencional, que ha dado lugar a la aparición de mecanismos de control internacional. A causa de esto, constituye una obligación erga omnes para el Estado velar por la protección de las personas que están dentro de su territorio. El capítulo I del Proyecto de Artículos sobre la Responsabilidad del Estado por Hechos Internacionalmente Ilícitos, en sus artículos 1o. y 2o. dice que: "todo hecho internacionalmente ilícito del Estado genera responsabilidad internacional". Aunque este comportamiento sea por acción u omisión, será atribuible al Estado.

14 Desde 1996, la Comisión de Derechos Humanos de Naciones Unidas (CDHNU) formulaba anualmente una Declaración sobre la Situación de Derechos Humanos en Colombia. La Comisión fue sustituida en marzo del 2006 por el Consejo de Derechos Humanos.

15 http://www.icj.org.

16 Sobre este tema se puede consultar el informe presentado por Caicedo, Luz Piedad y Acosta, Paola Andrea, Desplazamiento forzado en Colombia, Balance de la política pública desde los intereses y necesidades de las mujeres, Bogotá, Observatorio de Derechos Humanos de las Mujeres en Colombia, Corporación Sisma Mujer, septiembre de 2005. 
preocupante "el número extremado y persistentemente elevado de desplazados internos" exhortó a los grupos armados de abstenerse a cometer actos que provoquen desplazamientos y a no realizar confinamientos de población.

Las fuerzas militares y demás cuerpos de seguridad del Estado fueron responsables de 2,841 casos de violaciones, asimismo, los paramilitares de 1,510; durante ese mismo periodo se registraron 3,028 víctimas. Por otra parte, fuerzas militares fueron responsables de 645 infracciones, los paramilitares de 1,317 infracciones y los grupos guerrilleros de 1,066 infracciones al derecho internacional humanitario. Durante el primer semestre de 2004, el banco de datos del CINEP registró 1,000 casos de ejecuciones extrajudiciales y homicidios deliberados y 678 casos de presuntos combatientes muertos en acciones bélicas. ${ }^{17}$

La inmensa mayoría de las víctimas han sido campesinos, indígenas, miembros de comunidades afrocolombianas, pobladores de barrios pobres, indigentes, marginados del ciclo económico, niños de la calle, activistas sociales y políticos. Entre 1991 y 2002, fueron asesinados o desaparecidos más de 1,904 sindicalistas. La cifra de personas desplazadas internamente por el conflicto ronda los tres millones, es decir, entre el 6 y el $7 \%$ de la población total del país. Éste índice sitúa a Colombia en el tercer lugar del mundo, después de Sudán y de la República Democrática del Congo en cuanto al número de desplazados internos. ${ }^{18}$

Ahora bien, entre el 7 de agosto de 2002 y el 30 de septiembre de 2005, alrededor de 950,000 personas han sido desplazadas por razones de violencia en Colombia. ${ }^{19}$ Esto genera una crisis humanitaria crónica y sostenida, que puede profundizarse al extenderse el conflicto armado interno en el país siendo más crítica la situación al no tener la posibilidad de regresar a su lugar de origen porque no pueden reclamar sus tierras, ni cuentan con la acreditación de manera formal de los terrenos que han sido expulsados a la fuerza; forzándolos así, a tener que vivir en condiciones de alojamiento, educación y salud muy deficientes. ${ }^{20}$ La mayor

17 CINEP, Noche y Niebla, núm. 29, 2006, http:/www.nocheyniebla.org. En este mismo sentido, sobre los ataques dirigidos a cualquier población civil, véase Ambos, Kai, Los nuevos crímenes del derecho penal internacional, Bogotá, Ibáñez, 2004, pp. 30-32.

18 http://www.acnur.org.

19 CODHES, "Resumen ejecutivo del Boletín de la Consultoría para los Derechos Humanos y el Desplazamiento", núm. 64, 26 de octubre de 2005, http:/ www.codhes.org.

20 Corte Constitucional, Sentencia T-025 de 2004. 
parte se hacina en condiciones infrahumanas de vivienda, en las zonas más deprimidas de las capitales colombianas sin expectativa que mejore su situación. ${ }^{21}$

\section{Política de seguridad democrática}

El gobierno del presidente Álvaro Uribe Vélez adelantó una política llamada "seguridad democrática", que otorga prioridad a la inversión militar y al refuerzo del control de la población. En un país como el de Colombia, que tiene tantos problemas sociales, lo que podría generar ésta política gubernamental es el aumento de la desigualdad social, así como el incremento de la pobreza. Una política de seguridad democrática es un planeamiento interesante que tenemos para reivindicar, pero de manera indisoluble. Cuando uno permite que se escindan esas dos ideas, primero la seguridad a cualquier precio y luego la democracia, entramos en un modelo dictatorial y por ese camino no se llega a la democracia.

Según el autor Daniel Pecault, lo que plantea el presidente Uribe se da en el plano internacional, lo nuevo es que éste ya no presenta al país como un pobre país acosado por el narcotráfico y el crimen organizado, sino que ofrece a éste como portaviones para la guerra de Estados Unidos contra el terrorismo; Colombia es el aliado de Estados Unidos para desarrollar su política de seguridad a nivel hemisférico y su política contra el terrorismo a nivel mundial. ${ }^{22}$

21 Según la sentencia SU-1150 de 2000, con ponencia del magistrado Eduardo Cifuentes Muñoz, este desplazamiento interno implica violación de derechos fundamentales:... El desplazamiento forzado implica rupturas y destrucción del tejido social que se manifiestan en los cambios de las estructuras familiares, la recomposición poblacional de inmensas regiones, y la perversión de los poderes políticos y económicos. Además, a nivel comunitario, se han destruido procesos de organización, producción y participación propios de las comunidades rurales, a través de las cuales buscaban soluciones a sus necesidades básicas... La mayoría de las personas que se encuentran en situación de desplazamiento forzado terminan en condiciones infrahumanas, hacinadas en zonas marginales de las ciudades intermedias o capitales, donde la insatisfacción de las necesidades básicas es habitual, y su arribo influye decididamente en el empeoramiento de las condiciones generales de vida de la comunidad allí asentada: alojamiento, salubridad, abastecimiento de alimentos y agua potable, entre otros.

22 Romero, Marco, "Las dinámicas de reestructuración de la guerra en Colombia", Proyecto de Caminos de Desarrollo y Paz, Mediación de Conflictos, ejecutado por la Corporación Nuevo Arco Iris, Bogotá, CODHES, marzo de 2004. 
Según el juicio del alto comisionado de la ONU para los derechos humanos, esa política de seguridad democrática ignora los principios fundamentales del derecho humanitario mediante la eliminación de las distinciones entre civiles y combatientes y la militarización de la sociedad. Se restringe derechos y libertades, por medio de la concesión de poderes judiciales al Ejército, eliminación del control judicial de ciertas actuaciones y la limitación de la libertad de movimiento. ${ }^{23}$

El gobierno colombiano no es el único responsable de estas violaciones perpetradas constantemente en la sociedad, no obstante, desde el punto de vista del derecho internacional la jurisprudencia ha reconocido la existencia de la obligación erga omnes, derivada de las normas de ius cogens, a través de situaciones que por su naturaleza se consideran oponibles a todos los Estados, generando con ello consecuencias jurídicas de obligatorio cumplimiento para todos. ${ }^{24}$

De ahí que la protección y defensa de los derechos humanos es una obligación del Estado; a causa de esto, en caso de incumplimiento es quien responde ante la jurisdicción internacional contra la violación, reclamación y reparación. ${ }^{25}$ En palabras de Casado Raigón: “Ante todo... las normas de ius cogens, al igual que en los ordenamientos internos, suponen un límite a la autonomía de la voluntad; constituyen, sin duda alguna, el más fuerte límite que el medio colectivo en que los Estados vi-

23 La violación de una norma de derecho internacional humanitario genera responsabilidad del Estado y la obligación de indemnizar, porque al Estado le son imputables los actos cometidos por las personas que forman parte de las fuerzas armadas. Según los artículos 51, 52, 131 y 148 del I, II, III y IV Convenio de Ginebra, respectivamente, así como el artículo 91 del Protocolo I. De conformidad con el artículo 5o. del Estatuto de Roma, son crímenes de competencia de la Corte: el crimen de genocidio, los crímenes de lesa humanidad y los crímenes de guerra. Desafortunadamente, en el territorio colombiano se han perpetrado durante varios años graves actos de violencia cometidos como parte de un ataque generalizado o sistemático contra la población. Estos crímenes han sido atribuidos a grupos armados ilegales (guerrilla, paramilitares, etcétera), como también a servidores públicos del Estado, entre ellos integrantes de las fuerzas militares y de la policía nacional. Por lo tanto, estos actos de violación de los derechos humanos quedarán en la impunidad, porque la Corte tendrá competencia respecto de crímenes cometidos después de la entrada en vigor del estatuto.

24 Blas Altemir, A., La violación de los derechos humanos fundamentales como crimen internacional, Barcelona, Bosch, 1990, p. 91.

25 Proyecto de Artículos sobre la Responsabilidad del Estado por Hechos Internacionalmente Ilícitos. Capítulo III. Violaciones graves de obligaciones emanadas de normas imperativas de derecho internacional general. Artículos 31, 41 y 42. 
ven y desenvuelven su actividad, se impone al relativismo del derecho internacional, al voluntarismo y subjetivismo de los Estados soberanos". 26

En opinión del profesor Pérez González, la obligación del Estado de reparar, debe interpretarse en un sentido que no excluya otras posibles vías para hacer efectiva la obligación de reparar, distinta a la de la indemnización. Así, sería posible la imposición de sanciones en el caso de violaciones muy graves del derecho internacional humanitario calificables como crímenes internacionales. ${ }^{27}$

Como se ha mencionado anteriormente, no sólo los Estados son los responsables de las violaciones a los derechos humanos, sino que las acciones perpetradas por los individuos reconocidos como peligrosas para toda la comunidad internacional, implican a éstos como responsables. De acuerdo a lo establecido en la sentencia del Tribunal de Nuremberg del 30 de septiembre de 1946: "Crímenes contra el derecho internacional son cometidos por hombres, no por entidades abstractas, y sólo castigando a los individuos que cometieron dichos crímenes pueden ser puestas en vigor las provisiones del derecho internacional". ${ }^{28}$

Cuando estas acciones son cometidas por oficiales y el peligro internacional sea de la magnitud como lo describe el artículo 19 del proyecto de artículos sobre la responsabilidad internacional del Estado, ${ }^{29}$ pueden ser ambas consideradas como una acción de éste y como una maniobra perpetrada por individuos, conduciendo a dos diferentes tipos de responsabilidad: una acción del Estado junto con el crimen internacional, vinculando la responsabilidad del Estado y la responsabilidad penal, así como la responsabilidad penal de los individuos que cometieron esas violaciones.

La responsabilidad individual ha sido históricamente confirmada en los diferentes juicios por crímenes de guerra desde la Segunda Guerra Mundial; un ejemplo reciente de ello, la Corte Penal Internacional Permanente (International Criminal Court, ICC), por otro lado, el aumento

26 Casado Raigón, R., Notas sobre el ius cogens internacional, Córdoba, Casado, 1991, p. 11.

27 Pérez González, M., "La responsabilidad internacional de entes distintos de los Estados”, en Díez de Velasco, M., Instituciones de derecho internacional público, 11a. ed., Madrid, Tecnos, 1997, pp. 1102 y 1103.

28 Ambos, Kai, Temas de..., cit., nota 12, p. 123.

29 González Campos, Julio D. et al., op. cit., nota 12, p. 140. 
de jurisprudencia del Tribunal Penal Internacional para la antigua Yugoslavia y el de Rwanda. ${ }^{30}$

De manera general, estos tribunales han reconocido que el principio de culpabilidad individual requiere del conocimiento por parte del acusado de las circunstancias del delito. ${ }^{31}$ El Tribunal Militar Internacional para el Lejano Este (IMTFE) se refirió al principio de culpabilidad en el contexto de la cuestión de responsabilidad criminal de ciertas organizaciones nazis, el cual consagró como uno de los más importantes principios legales: "La culpabilidad es personal, y los castigos en masa deben ser evitados"; "El Tribunal debe hacer semejante declaración de criminalidad de un grupo u organización en la medida de lo posible de un modo que garantice que personas inocentes no serán castigadas". ${ }^{32}$

El caso que primero prestó atención de manera sustancial respecto de la responsabilidad individual fue el caso Tadic. ${ }^{33}$ En éste, se interpretó el artículo 7o. ${ }^{34}$ del Estatuto del Tribunal Internacional para el Enjuicia-

30 Bollo Arocena, Ma. Dolores, Derecho internacional penal. Estudio de los crímenes internacionales y de las técnicas para su represión, Bilbao, Universidad del País Vasco, 2004, pp. 423-435. En este mismo sentido, Ripoll Carulla, Santiago, El desarrollo de la potestad sancionadora del Consejo de Seguridad de las Naciones Unidas (contribución al estudio del concepto de sanción internacional), Bilbao, Instituto Vasco de Administración Pública, 2003, pp. 122-125.

31 Un ejemplo de esto, se vio en el caso de Eichmann, quien sabía de la solución final de los judíos; cualquier forma de participación en esta solución final fue considerada suficiente para justificar la responsabilidad penal. Por ello, Eichmann fue condenado como autor principal sobre la base de varios actos de apoyo o cooperación.

32 Ambos, Kai, Temas de..., cit., nota 12, pp. 126 y 127.

33 Dusan Tadic fue un miembro de bajo nivel de la milicia serbo-bosnia. En otras circunstancias, él habría sido otro delincuente más lleno de odio que comete actos grotescos. Pero Tadic fue el primer individuo juzgado ante el Tribunal Criminal Internacional ad hoc para la ex Yugoslavia (ICTY), creado por parte del Consejo de Seguridad de la ONU. Fue juzgado por su participación en el abuso de musulmanes bosnios en el Centro de Detención Omarska, durante la guerra civil en Bosnia.

34 Artículo 7.1 dice: Responsabilidad penal individual. 1. La persona que haya planeado, instigado u ordenado, la comisión de algunos de los crímenes señalados en los artículos 20. a 5o. del presente Estatuto, o lo haya cometido o haya ayudado en cualquier forma a planearlo, será individualmente responsable de ese crimen. 2. El cargo oficial que desempeñe el inculpado, ya sea jefe de Estado o de Gobierno o de funcionario responsable del gobierno, no lo eximirá de responsabilidad penal ni atenuara la pena. 3. El hecho de que cualquiera de los actos mencionados en los artículos 20. a 5o. del presente Estatuto haya sido cometido por un subordinado, no eximirá de responsabilidad penal a su superior, si éste sabía o tenía razones para saber que el subordinado iba a cometer tales 
miento de los Presuntos Responsables de Violaciones Graves del Derecho Internacional Humanitario cometidas en el territorio de la ex Yugoslavia, y al referirse a la jurisprudencia desde Nuremberg, sostiene que la responsabilidad penal individual tiene una base en el derecho internacional consuetudinario. Respecto a la responsabilidad de Tadic, la Sala distinguió entre los delitos cometidos directamente por éste y aquéllos que no cometió de manera directa pero en cuya comisión estuvo presente en su ejecución o de algún modo estuvo involucrado. Mientras que la responsabilidad por el segundo supuesto, la Sala de Primera Instancia tuvo que determinar si el acusado estaba suficientemente implicado con los crímenes como para poder ser considerado responsable penalmente. ${ }^{35}$

Como hemos visto, en el plano de la responsabilidad penal individual, ${ }^{36}$ todas las personas que cometan y hayan cometido crímenes internacionales, incluso aquellos que desempeñen cargos públicos o formen parte de las fuerzas armadas, deben ser juzgadas dentro del marco del derecho penal internacional.

\section{Desplazamiento interno}

Las normas sobre protección de personas desplazadas se encuentran dispersas en diferentes regímenes especializados, como los derechos humanos o en el derecho internacional humanitario. Después de un largo periodo y la lucha de distintas organizaciones tanto nacionales como internacionales, el Estado introdujo amplias reformas legislativas, así como mecanismos de protección específica para los desplazados, ${ }^{37}$ en especial

actos o los había cometido, y no adoptó medidas necesarias y razonables para impedir que se cometieran, o para castigar a quienes los perpetraron. 4. El hecho de que el inculpado haya actuado en cumplimiento de una orden impartida por un gobierno o por un superior, no lo eximirá de responsabilidad penal, pero podrá considerarse circunstancia atenuante si el Tribunal Internacional así lo determina o exige la equidad.

35 Ibidem, pp. 144 y 145.

36 Artículo 25. Responsabilidad penal individual. Estatuto de la Corte Penal Internacional del 17 de julio de 1998.

37 La Ley 387, de 1997, creó diferentes mecanismos para la protección de la población desplazada, entre los cuales se encuentra el Sistema Nacional de Atención Integral a la Población Desplazada por la Violencia, la cual se encarga de atender de manera integral a la población que ha sido desplazada, para que por medio del retorno voluntario o el reasentamiento, logre su integración en la sociedad colombiana; entre otras, el fortalecimiento del desarrollo integral de las zonas de conflicto. A su vez, el Consejo Nacional 
atención, a prevenir el éxodo masivo de la población. ${ }^{38}$ A pesar de esto, las reformas y estrategias creadas no han tenido resultados positivos hasta la fecha.

La Ley 387 de 1997 estableció las bases de la política estatal de atención a las personas desplazadas por razón del conflicto armado interno, incluidas las violaciones de los derechos humanos y del derecho humanitario. Esta Ley instaura el Sistema Nacional de Atención Integral a la Población Desplazada por la Violencia que establece dos puntos principales: uno relativo a los recursos, y otro a las entidades encargadas de hacer frente al problema, desarrollando estrategias de prevención, atención inmediata, consolidación y estabilización socioeconómica.

En el ámbito nacional, las entidades competentes son: el Consejo Nacional para la Atención Integral a la Población Desplazada por la Violencia y la Consejería Presidencial. El Consejo será el órgano consultivo y asesor, encargado de formular la política y garantizar la asignación del presupuesto a los programas que las entidades responsables del funcionamiento tienen a su cargo. A su vez, le corresponde a la Consejería Presidencial la coordinación, desarrollo y operación del Sistema Nacional de Información sobre Población Desplazada por la Violencia. ${ }^{39}$

Aunque la Ley 387 de 1997 tiene un marco legal y normativo sobre el desplazamiento interno en Colombia excepcional, y se basa en gran

para la Atención Integral al Desplazado, creado como órgano consultivo y asesor, es el encargado de formular políticas de desarrollo, y garantizar la asignación presupuestal que las diferentes entidades tengan a cargo para la protección de los desplazados.

38 El fenómeno del desplazamiento interno ha sido estudiado en el Seno de Naciones Unidas desde la década de los ochenta. Este ha creado varias iniciativas con respecto a los desplazados, siendo una de ellas la figura del representante del secretario general de la ONU para los desplazados internos; quien diseñó un modelo para la atención a las personas desplazadas, el cual contiene un conjunto de principios rectores del desplazamiento interno, que deben orientar la actuación del Estado en cuyos territorios se producen éxodos masivos involuntarios. Las personas que se hallen en situación o riesgo de desplazamiento tienen derecho a recibir atención especial por parte del Estado, en consideración a la vulnerabilidad a la que están expuestas y al hecho de que el Estado ha fallado en su deber de protegerlas frente al éxodo masivo (principios rectores 3o., 10 y 27). En este mismo sentido, véase el informe del representante del secretario general Deng, Francis, "Derechos humanos, éxodos en masa y personas desplazadas", en E/CN.4/1998/53/Add.1, 11 de febrero de 1998.

39 Sección 2 del capítulo II. Ley 387 de 1997. Esta red toma las labores que sobre esta área venía realizando la Dirección Nacional para la Atención de Desastres, en colaboración con la Conserjería Presidencial para los Derechos Humanos. 
medida en los principios rectores del desplazamiento interno, ${ }^{40}$ su implementación está muy atrasada. Las causas principales son: la disparidad de recursos disponibles y la cantidad de personas afectadas; al ser registradas las personas como desplazadas, los beneficiarios reciben ayuda de emergencia durante tres meses, los cuales son prorrogables tres meses más. No obstante, en la mayoría de los casos una vez que se les ha prestado asistencia no se les ayuda a la integración económica y social, constituyendo esto una solución temporal más no contundente que les permita mejorar su situación. ${ }^{41}$

La Ley 387, de 1997, considera:

Artículo 1. Del Desplazado. Es desplazado toda persona que se ha visto forzada a migrar dentro del territorio nacional abandonando su localidad de residencia o actividades económicas habituales, porque su vida, su integridad física, su seguridad o libertad personal han sido vulneradas o se encuentran directamente amenazadas, con ocasión de cualquiera de las siguientes situaciones: conflicto armado interno, disturbios y tensiones interiores, violencia generalizada, violaciones masivas de los derechos humanos, infracciones al derecho internacional humanitario $u$ otras circunstancias emanadas de las situaciones anteriores que puedan alterar o alteren drásticamente el orden público. ${ }^{42}$

El fenómeno del desplazamiento interno en Colombia es de gran magnitud, ha erosionado el entorno social y la economía, a causa de éste, se ha empobrecido la población. Casi todos los departamentos del país se han visto afectados por esto, pero los principales receptores de desplazados son: Antioquía, Cauca, Magdalena, Bolívar y Chocó. Sin embargo, más que a causa del conflicto armado del país, el desplazamiento forzado es una estrategia deliberada empleada por los diferentes grupos ilegales presentes en la zona de hostilidades. ${ }^{43}$ Es un acto premeditado que se utiliza a diario y que por esto dificulta establecer con certeza el número de

40 Principios rectores sobre desplazamiento interno, extracto del documento E/CN.4/1998/53/Add.2, 11 de febrero de 1998.

41 ACNUR, Consideraciones sobre la Protección Internacional de los Solicitantes de Asilo y los Refugiados Colombianos, Ginebra, septiembre de 2002, p. 13.

42 http://www.derechoshumanos.gov.co. En línea: 12-05-06.

43 Véase el informe general sobre los desplazamientos internos, perfiles del desplazamiento; misiones de seguimiento a Colombia. E/CN/2000/83/Add.1, enero de 2000. 
desplazados, lo que conlleva a que muchos de éstos no se registren, y por tanto, no accedan a los diferentes programas sociales de ayuda.

Las causas del desplazamiento son múltiples: algunas veces las personas lo hacen de manera individual, otras con toda la familia; en otras ocasiones la comunidad decide huir, siendo unas de las principales causas: amenazas recibidas a la familia, temor a los enfrentamientos armados y encontrarse en medio del conflicto, las masacres, amenazas individuales, los ataques directos a la población, y el temor a ser reclutados por parte de los grupos guerrilleros. Una de las mayores causas del desplazamiento de comunidades enteras es el ataque a las instalaciones y a las infraestructuras civiles, lo que genera el aislamiento económico y necesidades para la comunidad, las cuales se ven obligadas a dejar sus tierras. $^{44}$

Como se puede observar, la ley colombiana no tiene en cuenta el desplazamiento muchas veces espontáneo, provocado de manera directa $\mathrm{o}$ indirecta por agentes al margen de la ley, ${ }^{45}$ es decir, el Estado se atribuye en exclusiva las obligaciones y excluye a los particulares de sus deberes. ${ }^{46}$ Es sabido que en muchos casos los grupos armados ilegales se ven involucrados de manera directa o indirecta en los desplazamientos forzados. ${ }^{47}$ Tales ataques pueden utilizarse de manera indiscriminada o bien deliberadamente y su intención es intimidar a la población civil que es vista como la base social del opositor. ${ }^{48}$

44 Ibidem, p. 12.

45 Los agentes al margen de la ley o entidades no estatales, como guerrilla, paramilitares, delincuentes comunes, Fuerzas Armadas Revolucionarias de Colombia (FARC).

46 Al parecer, el Estado colombiano no ha tenido en cuenta los desplazamientos espontáneos provocados por los grupos al margen de la ley, los cuales son responsables de la violación al derecho internacional humanitario por el ataque de manera indiscriminada a la población civil que conlleva al desplazamiento permanente de la misma; por ello, incurren en responsabilidad penal individual por todas las violaciones a los derechos humanos.

47 Esto está tipificado en el Código penal en el artículo 142. Utilización de medios y métodos de guerra ilícitos. El que con ocasión, y en desarrollo de conflicto armado, utilice medios o métodos de guerra prohibidos o destinados a causar sufrimientos o pérdidas innecesarios o males superfluos incurrirá, por esa sola conducta, en prisión de seis (6) a diez (10) años, multa de cien (100) a doscientos (200) salarios mínimos legales mensuales vigentes, e inhabilitación para el ejercicio de derechos y funciones públicas de (5) cinco a diez (10) años.

48 ACNUR, op. cit., nota 41, pp. 9-10. 
Los actores no estatales utilizan el desplazamiento en el marco de luchas por el control territorial, de áreas estratégicas desde el punto de vista militar, zonas de tráfico de armas o de productos ilegales, como también político - destrucción de bases sociales reales o potenciales del contrario- . Por ejemplo, los paramilitares y el Estado lo utilizan en regiones con fuerte presencia de actores sociales y con tradición organizativa en sindicatos, organizaciones campesinas o indígenas, como el departamento del Cauca. Otra causa del desplazamiento es la lucha por el control de la tierra y los recursos en zonas de acumulación económica. De manera especial aquellas zonas de extracción de recursos naturales como el agua, petróleo y el control de cultivos ilícitos. ${ }^{49}$

Teniendo en cuenta el derecho internacional humanitario, ${ }^{50}$ estos grupos están obligados a tomar medidas con respecto al territorio que controlan, y a limitar las graves consecuencias de la guerra sobre la población civil, de conformidad al artículo 1o. del Protocolo II adicional a los Convenios de Ginebra. ${ }^{51}$

49 Rojas, Jorge et al., "Conflicto armado y desplazamiento forzado interno en Colombia”, Esta guerra no es nuestra. Niños y desplazamiento forzado en Colombia, Bogotá, CODHES-UNICEF, 2000.

50 Según el derecho internacional humanitario de origen convencional o consuetudinario, aplicado en los conflictos armados, internacionales o no internacionales, y que limita, por razones humanitarias, el derecho de las partes en conflicto a elegir libremente los métodos y los medios utilizados en la guerra, y que protege a las personas y a los bienes afectados, o que pueden estar afectados, por el conflicto. En los Convenios de Ginebra en sus artículos 2.1 y 1o. del Protocolo II. Adicional, se exige la responsabilidad directa de obligaciones, a los entes no estatales.

51 Artículo 1. Ámbito de aplicación material. El presente Protocolo, que desarrolla y completa el artículo 3o. común a los Convenios de Ginebra del 12 de agosto de 1949, sin modificar sus actuales condiciones de aplicación, se aplicará a todos los conflictos armados que no estén cubiertos por el artículo 1o. del Protocolo adicional a los Convenios de Ginebra del 12 de agosto de 1949 relativo a la protección de las víctimas de los conflictos armados internacionales (Protocolo I) y que se desarrollen en el territorio de una Alta Parte contratante entre sus fuerzas armadas y fuerzas armadas disidentes o grupos armados organizados que, bajo la dirección de un mando responsable, ejerzan sobre una parte de dicho territorio un control tal que les permita realizar operaciones militares sostenidas y concertadas, y aplicar el presente Protocolo./ Artículo 2. El presente Protocolo no se aplicará a las situaciones de tensiones internas y de disturbios interiores, tales como los motines, los actos esporádicos y aislados de violencia, y otros actos análogos, que no son conflictos armados. 
La legislación colombiana presta especial atención a la protección y la seguridad física de las personas desplazadas ${ }^{52}$ "con respecto a las cuales existan razones fundadas para temer por su seguridad", a través de la Dirección General de la Unidad Administrativa Especial para los Derechos Humanos del Ministerio del Interior, cuya evaluación se hará en estrecha colaboración con el Ministerio Público, la Iglesia y las ONG. ${ }^{53}$ Sin embargo, considerar la protección y seguridad física de las personas como esencia de las funciones vitales no es suficiente, la vida como tal, debe ser interpretada de una manera global, en la cual se incluya el derecho a la vida y a la calidad de la misma, teniendo en cuenta los derechos conexos que están inmersos en ésta, como también las libertades fundamentales.

La Corte Constitucional se ha pronunciado al respecto en la sentencia T-025/04, diciendo que la situación de los desplazados en Colombia es:

Un estado de cosas inconstitucional en la situación de la población desplazada debido a la falta de concordancia entre la gravedad de la afectación de los derechos reconocidos constitucionalmente y desarrollados por la Ley, de un lado, y el volumen de recursos efectivamente destinado a asegurar el goce efectivo de tales derechos y la capacidad institucional para implementar los correspondientes mandatos constitucionales y legales, de otro lado.

Es decir, la magnitud del daño causado a los más de tres millones de colombianos desplazados por causa del conflicto armado interno en Colombia, no ha sido remediada por las normas existentes ni por el presupuesto asignado para tal fin. Por tal razón, y en primer lugar, la Corte or-

52 La Corte Constitucional Colombiana, en la sentencia (C-574/92, 28 de octubre) sobre la exequibilidad del Protocolo I de 1977, hace una interpretación bastante progresista de los siguientes artículos de la Constitución Nacional: artículo 93 (sobre la primacía del derecho internacional convencional de los D. H.), artículo 94 (la aplicabilidad de derechos no expresamente consagrados en la Constitución, pero contenidos en tratados, ratificados por Colombia, inherente a la persona humana) y artículo 214.2 (el respeto en todo caso del DIH y su incorporación automática). La Corte considera que los Principios de la ONU forman parte del bloque constitucional, por tanto, los toma como criterios interpretativos de la Constitución colombiana de 1991.

53 Prieto Sanjuán, Rafael A., "Conflicto armado en Colombia y desplazamiento forzado: ¿Qué Protección?”, Revista del Instituto Interamericano de Derechos Humanos, Bogotá, vol. 12, 1998, p. 45. 
dena implementar un plan de acción que responda a las necesidades de la población afectada en los términos que ésta determina: "a más tardar el 31 de marzo de 2004, el Consejo Nacional para la Atención Integral a la Población Desplazada por la Violencia habrá de precisar la situación actual de la población desplazada inscrita en el Sistema Único de Registro, determinando su número, ubicación, necesidades y derechos según la etapa de la política correspondiente".

$\mathrm{Y}$ en segundo lugar:

Fijar la dimensión del esfuerzo presupuestal que es necesario para cumplir con la política pública encaminada a proteger los derechos fundamentales de los desplazados... definir el porcentaje de participación en la apropiación de recursos que corresponde a la Nación, a las entidades territoriales y a la cooperación internacional... indicar el mecanismo de consecución de tales recursos, y prever un plan de contingencia para el evento en que los recursos provenientes de las entidades territoriales y de la cooperación internacional no lleguen en la oportunidad y en la cuantía presupuestadas, a fin de que tales faltantes sean compensados con otros medios de financiación. ${ }^{54}$

Uno de los últimos pronunciamientos de la Corte Constitucional sobre el tema es el auto núm. 176 del 29 de agosto de 2005, el cual ordena al ministro de Hacienda, al director del Departamento de Planeación Nacional y a los miembros del Consejo Nacional para la Atención Integral a la Población Desplazada ${ }^{55}$ cumplir el fallo de la sentencia del 2004.

El auto ordenó entregar, antes del 1o. de diciembre de 2005, un cronograma que señale los mecanismos y los tiempos para la asignación de recursos para la implementación de la política pública de atención a la población desplazada. Ordena a Planeación Nacional que actualice el estimativo calculado, de tal forma que incluya a las personas desplazadas que deben ser atendidas en cada periodo fiscal. Y ordena a las instituciones públicas responsables de atender a la población desplazada, brindar

54 Sentencia de la Corte Constitucional Colombiana. T-025/ 2004, del 25 de febrero.

55 El Consejo Nacional de Atención a la Población Desplazada se creó por medio del artículo 6o. de la Ley 387 de 1997, por medio de la cual se adoptan medidas para la prevención del desplazamiento forzado; la atención, protección, consolidación y estabilización socioeconómica de los desplazados internos. 
toda la información a los responsables de implementar la política pública en mención. ${ }^{56}$

La Corte consideró que si bien el gobierno nacional ha realizado esfuerzos presupuestales para atender la crisis humanitaria que soportan los desplazados internos, aquéllos no son suficientes, pues no se ha superado el estado de cosas inconstitucional, es decir, los derechos humanos de los desplazados en Colombia continúan siendo vulnerados y desconocidos por las instituciones del Estado, en donde se ve una progresiva pérdida de los derechos fundamentales, como la libertad, el derecho al trabajo, a tener una vida digna y a participar en la vida política del país.

La Sala Tercera de Revisión profirió el 29 de agosto de 2005 tres autos dirigidos a distintas autoridades responsables de programas o componentes de atención a la población desplazada, tanto de orden nacional como territorial, para que adoptaran correctivos a los problemas encontrados por la Corte Constitucional con base en los informes presentados por las entidades del gobierno así como la Procuraduría General de la Nación, la Defensoría del Pueblo, ${ }^{57}$ las organizaciones de desplazados y el ACNUR, en relación con las diferentes órdenes impartidas por la Corte en la sentencia T-025 de 2004, con el fin de garantizar la superación del estado de cosas inconstitucional a un ritmo más acelerado y posible. ${ }^{58}$

El primer auto fue dirigido hacia el ministro del Interior y de Justicia, ${ }^{59}$ para que dentro de unos plazos perentorios, diseñe, implemente y

56 Montaña, Tatiana, La sentencia de los desplazados, Bogotá, Indepaz, 2005, p. 1.

57 En respuesta a la solicitud de la Corte Constitucional hacia el procurador general de la Nación y la Defensoría del Pueblo, para que dentro de sus competencias hicieran un análisis de cómo se venía avanzando en el cumplimiento de las órdenes impartidas en la sentencia T-025 de 2004, el procurador general de la Nación y el defensor del pueblo enviaron cuatro informes conjuntos con las conclusiones de ese proceso de evaluación, así como tres informes individuales y dos informes de conclusión presentados durante la audiencia de información del 29 de junio de 2005.

58 Corte Constitucional, Órdenes finales para el cumplimiento de la sentencia T-025 de 2004, Bogotá, Comunicado de prensa, 13 de septiembre de 2005.

59 El ministro de Interior y de Justicia deberán realizar distintas acciones en plazos, las cuales dependerán de la complejidad de las mismas, del nivel de avance o atraso de cada entidad territorial en el cumplimiento de las metas de atención a la población desplazada de conformidad con la sentencia T-025 de 2004. El plazo mínimo es de un mes, y más largo de un año. En el transcurso de estos plazos, el ministro del Interior y de Justicia deberá tomar otras medidas de evaluación y diseño de estrategias de coordinación de esfuerzos presupuestales y administrativos a nivel territorial y nacional. Los plazos indicados regirán a partir de la notificación del auto. 
aplique prontamente una estrategia de promoción y coordinación de esfuerzos nacionales y territoriales que conduzca a que las entidades territoriales asuman un mayor compromiso tanto presupuestal como administrativo para la atención a la población desplazada y la garantía efectiva de sus derechos. ${ }^{60}$

Pese a los esfuerzos que se han llevado a cabo, no se ha podido superar las falencias institucionales tales como: capacidad administrativa, capacitación del personal, niveles de cobertura, por ello la Corte le pidió al Consejo Nacional para la Atención integral a los Desplazados por la Violencia $^{61}$ que estudie la viabilidad de la respuesta del Estado, o la definición de nuevos compromisos. La Corte Constitucional, en ejercicio de su función de guardiana de la carta política, ${ }^{62}$ busca dar solución a situaciones en las cuales "la vulneración de los derechos fundamentales tengan un carácter general, en tanto que afecta a una multitud de personas, y cuyas causas sean de naturaleza estructural que, por lo regular, no se originan de manera exclusiva en la autoridad demandada y, por lo tanto, su solución exige la acción mancomunada de distintas entidades".

Los fallos dictados por la Corte Constitucional frente al problema de los desplazados hacen tránsito a cosa juzgada constitucional, esto es únicamente en la parte resolutiva de las sentencias de la Corte. En cuanto a la parte motiva, ésta constituye criterio auxiliar para la actividad judicial y para la aplicación de formas en general. ${ }^{63}$ No obstante, en caso de que las autoridades incumplan los fallos dictados por la Corte, incurrirán en desacato sancionable con arresto hasta de seis meses y multa hasta de 20

60 Con relación a las órdenes relativas al esfuerzo presupuestal necesario para implementar las políticas de atención a la población desplazada, la Corte consideró que se han llevado a cabo esfuerzos importantes y resultados concretos, pero concluyó que es necesario en el ámbito presupuestal continuar avanzando de manera específica, sostenida y eficiente en la superación del estado de cosas inconstitucional. Asimismo, que se haga una descripción explícita de la propiedad asignada por cada organismo de atención a la población desplazada, de tal manera que exista claridad acerca de los recursos asignados por cada entidad, y no se confunda tales recursos con los asignados a la población vulnerable en general.

61 Consejo Nacional para la Atención integral a los Desplazados por la Violencia, creado a partir de la Ley 387 de 1997.

62 La Corte Constitucional es el órgano de la jurisdicción constitucional, al que se le confía "la guarda de la integridad y supremacía de la Constitución" (artículos 241 y 241.A de la Constitución Nacional).

63 Corte Constitucional Sentencia C-37 de 1996. 
salarios mínimos mensuales y sin perjuicio de las sanciones penales a que hubiere lugar. La sanción será impuesta por el juzgado o tribunal que conoció por primera vez del asunto mediante trámite incidental y será consultada al superior jerárquico quien decidirá dentro de los tres días siguientes si debe revocarse la sanción. Así es cómo en el caso de los desplazados se han presentado diferentes acciones de tutela, ${ }^{64}$ donde se reclama el cumplimiento de la Ley 387 de 1997, por la cual se adoptan medidas para la prevención del desplazamiento forzado, la atención y protección.

La Sección Tercera de la Sala de lo Contencioso Administrativo advirtió que a los desplazados les asisten derechos prestacionales; el artículo 33 de la Ley 387 le concede la facultad a los desplazados, las organizaciones no gubernamentales y las entidades oficiales encargadas de la defensa o promoción de los derechos humanos, ejercitar la acción de cumplimiento para exigir judicialmente la plena efectividad de sus derechos. ${ }^{65}$

Es inaceptable que las entidades que componen el Sistema Nacional de Atención Integral a la Población Desplazada por la Violencia justifiquen el incumplimiento de estos deberes prestacionales con la prohibición que establece el parágrafo del artículo 90. ${ }^{66}$ de la Ley, ya que para la

64 Véase las siguientes sentencias: T-258 de 5 de marzo de 2001, donde la Sala Séptima de Revisión de la Corte Constitucional ordena conceder a una persona desplazada el amparo de los derechos fundamentales a la vida y a la integridad personal de John Jairo Franco y de su hijo menor. T-1635 de 27 de noviembre de 2000. Acción de tutela incoada por el defensor del pueblo regional de Bogotá, contra la red de seguridad social, en defensa de los derechos fundamentales de las personas afectadas y desplazadas de diferentes regiones de Colombia.

65 La sección tercera de la Sala de lo Contencioso Administrativo, de 4 de febrero de 1999, AC-573, cuyo magistrado ponente fue Daniel Suárez Hernández, advirtió que a los desplazados les asisten derechos prestacionales. El artículo 87 de la Constitución Política, desarrollado por la Ley 393 de 1997, señala que toda persona puede ejercer la acción de cumplimiento con el fin de exigir a las autoridades públicas y a los particulares, cuando actúen o deban actuar en ejercicio de funciones públicas, el cumplimiento de la ley o de un acto administrativo, con el fin de que el contenido de éste o aquélla tenga concreción en la realidad. Es necesario, para la procedencia de esta acción, que la norma o el acto administrativo cuyo cumplimiento se persigue, contenga una obligación o deber claro, expreso y exigible respecto de la actividad, y que no se trate de un precepto de carácter general o contenido de una facultad discrecional.

66 Ley 393 de 1997, artículo 9o. Improcedibilidad. La acción de cumplimiento no procederá para la protección de derechos que puedan ser garantizados mediante la acción 
atención a la población desplazada el artículo 21-ib creó un Fondo Nacional ${ }^{67} \mathrm{y}$, la razón de su existencia es la ejecución de los programas y de los recursos respectivos.

\section{LA COMUNIDAD INTERNACIONAL Y LA AYUDA HUMANITARIA}

Debido a la crisis que ha vivido Colombia en estos últimos años, ha generado la intervención de la comunidad internacional en el desarrollo de estrategias que tiendan a disminuir la pobreza y el caos generado por la guerra. En relación a esto, merece la pena resaltar que el proceso de internacionalización de los principales problemas del conflicto se vio alimentado por cuatro elementos: la globalización, el problema mundial de las drogas ilícitas, la crisis humanitaria y la situación del medio ambiente.

El país ha vivido una serie de hechos - el proceso de elecciones de 1990 durante la cual fueron asesinados tres candidatos, el incremento del poder de los grupos al margen de la ley como los guerrilleros, narcotraficantes, paramilitares, entre otros, y la recesión económica de los últimos años - que "sumados a la globalización, pusieron el problema colombiano en la agenda internacional, y a su vez produjeron una internacionalización de los principales problemas nacionales". ${ }^{68}$ Pese a todos estos problemas de gran relevancia, el tema de los desplazados es tal vez uno

de tutela. En estos eventos, el juez le dará a la solicitud el trámite correspondiente al derecho de tutela. No obstante, si la norma con fuerza material de ley o el acto administrativo implican un gasto, la limitante legal no es predicable cuando se trata de la ejecución presupuestal. Una vez elaborado un presupuesto o apropiado el gasto, el objetivos de éstos es la de ser efectivamente destinados a la satisfacción de la función social para el cual están concebidos. De manera que se pretende el cumplimiento en concreto, ya que una vez ordenado, presupuestado y apropiado el gasto, todas las autoridades encargadas de su ejecución han de cumplirlo.

67 Artículo 21. De la creación y naturaleza. Créase el Fondo Nacional para la Atención Integral a la Población Desplazada por la Violencia que funcionará como una cuenta especial, sin personería jurídica, administrada por el Ministerio del Interior, como un sistema separado de cuentas./ Parágrafo. La Consejería Presidencial para los Desplazados coordinará la ejecución de los recursos de este fondo.

68 Puyana Valdivieso, José Ricardo, "Colombia frente a los retos del multilateralismo", Oasis 2005-06, Bogotá, Universidad Externado de Colombia, Facultad de Finanzas, Gobierno y Relaciones Internacionales, Centro de Investigaciones y Proyectos Especiales, núm. 11, pp. 85-102. 
de los más preocupantes, generando así la intervención de organismos internacionales.

Por todos los problemas presentes del país, se llevó a cabo una reunión de coordinación y cooperación internacional realizada en Cartagena, en la cual se empieza a registrar el aumento de recursos de cooperación internacional, algunos de los cuales se reorientaron hacia áreas prioritarias en el país como el desarrollo productivo y alternativo, el desplazamiento forzoso ${ }^{69}$ la asistencia humanitaria y el fortalecimiento del Estado social de derecho. De acuerdo con las cifras reportadas por la Dirección de Cooperación Internacional de la Agencia Presidencial para la Acción Social y la Cooperación Internacional, hubo un incremento sustancial de los desembolsos efectivos de cooperación (ayuda oficial de desarrollo) de 125 a 350 millones de dólares. De estos recursos, 95 millones de dólares se han reorientado hacia las mayores necesidades en el país. $^{70}$

A nivel interno se han aumentado los recursos de cooperación y se ha conseguido una mayor coordinación con los países y organizaciones que hacen parte del Grupo de los 24 o G-24, hecho que ha facilitado la interlocución e identificación de áreas prioritarias para Colombia con los países y organizaciones cooperantes. En el transcurso de 2005, la acción social realizó 42 reuniones bilaterales con la mayoría de las fuentes de cooperación en el país.

\section{Organizaciones internacionales}

A causa del aumento de la violencia y el conflicto en el Estado colombiano, muchas instituciones han entrado a apoyar al gobierno, a través de diferentes proyectos de desarrollo. Dentro de éstas, estuvo presente desde 1996 la Comisión de Derechos Humanos, quien formula anualmente una Declaración sobre la Situación de Derechos Humanos en Colombia; la primera Declaración presentada en el Quincuagésimo segundo periodo de sesiones de la Comisión tuvo como propósito principal "establecer... una oficina permanente en Colombia con el mandato de

69 Sobre el desplazamiento interno y la respuesta ofrecida por la comunidad internacional, se puede consultar entre otros a Cohen R. y Deng, Francis, Masses in Flight: The Global Crisis of Internal Displacement, Brookings Institution Press, 1998; y Peral, L. A., Éxodos masivos, supervivencia y mantenimiento de la paz, Madrid, Trotta, 2001.

70 Acción Social, http:/www.acciónsocial.gov.co. 
ayudar a las autoridades colombianas a elaborar políticas y programas para la promoción y protección de los derechos humanos y de observar las violaciones de los mismos en el país, presentando informes analíticos al alto comisionado". ${ }^{71}$

Otra entidad presente es la Organización Internacional para las Migraciones (OIM), que participa en actividades conjuntas con el Fondo Global contra la Malaria, el VIH-SIDA y la Tuberculosis para asistir y prevenir a este sector de la población y a otros sectores vulnerables. A su vez, ha participado en numerosas campañas de sensibilización con organizaciones gubernamentales y de la comunidad internacional para prevenir la trata de personas o la vinculación de los menores a los grupos armados ilegales. Trabaja por la integración de las poblaciones móviles, retornados, niños desvinculados, desplazados o desmovilizados con la creación y desarrollo de centros de referencia y crientación, los cuales apoyan instituciones gubernamentales en su esfuerzo por ofrecer soluciones de reintegración a las víctimas de la migración forzada..$^{72}$

La OIM es parte activa del trabajo que desarrollan organismos internacionales, Gobierno y ONG para asistir a los desplazados internos, al tiempo que contribuye al fortalecimiento de las acciones que desarrolla la Red de Solidaridad Social (RSS) entre otras entidades del Gobierno. ${ }^{73}$ Ésta desarrolla el programa de fortalecimiento de la paz con miras a apoyar la transición y recuperación, y ayuda a las instituciones gubernamentales como el Instituto Colombiano de Bienestar Familiar (ICBF) o la Defensoría del Pueblo en la creación de programas que permitan el fortalecimiento de las acciones para asistir y prevenir a los menores de la vinculación a los grupos armados ilegales; por otro lado, procura asistencia técnica al Ministerio del Interior y de Justicia en los procesos de desmovilización individuales.

Las agencias de la ONU han estado presentes en Colombia desde el momento en que se vio el riesgo inminente de extensión del conflicto a otros países fronterizos. A causa de ello, se creó una oficina del alto co-

71 Se llevó a cabo el establecimiento en Colombia de una Oficina del Alto Comisionado de las Naciones Unidas para los Drechos Humanos, http:/www.hchr.org.co.

72 Véase el informe de derechos humanos: Éxodos en Masa y Personas Desplazadas. La Cuestión de los Desplazamientos Internos, E/CN/4/1995/50.

73 http:/www.oim.org.co. 
misionado para los derechos humanos, ${ }^{74}$ la cual trabaja por el desplazamiento interno ${ }^{75}$ mediante la asistencia y protección. ${ }^{76} \mathrm{El}$ sistema de Naciones Unidas está representado en Colombia por: PNUD, ${ }^{77}$ UNICEF, ${ }^{78}$ PMA, ${ }^{79} \mathrm{FAO}$, y otras agencias bajo la coordinación de ACNUR, quien a

74 El Alto Comisionado de Naciones Unidas abrió una oficina en Bogotá en 1997 y realiza informes anuales en los que denuncia las violaciones a los derechos humanos por todas las partes en conflicto, las cuales incluye al Estado y reclama el cumplimiento de las normas internacionales. De todos los organismos de Naciones Unidas, el ACNUR es el que ha asumido la función más amplia de asistencia y protección a los desplazados internos; a pesar de que su mandato no incluye a los desplazados internos, ha intervenido cada vez más en situaciones que los afectan.

75 Un desplazado interno es aquella persona que se ha visto obligada a huir de su residencia habitual, ante hechos naturales o provocados por el hombre que han puesto en peligro su vida y otros derechos fundamentales conexos, o ante el riesgo de que esto sobrevenga. La diferencia respecto del refugiado es que no traspasa las fronteras nacionales, este desplazamiento es provocado de manera interna. Por el contrario, una persona refugiada es aquella persona que "debido a temores fundados de ser perseguida por razones de raza, religión, nacionalidad, pertenencia a determinado grupo social u opiniones políticas, se encuentra fuera del país de su nacionalidad, y no pueda o, a causa de dichos temores, no quiera acogerse a la protección de dicho país". Los refugiados son protegidos por el derecho internacional de los refugiados, dentro de los que se encuentran: la Convención sobre el Estatuto de los Refugiados adoptada el 28 de julio de 1951 y el Protocolo Adicional a ésta de 1967; y el Alto Comisionado de Naciones Unidas para los Refugiados, creado en 1950. Véase Manual de Procedimientos y Criterios para Determinar la Condición de Refugiado, ACNUR, 1979.

76 La categoría de desplazados internos suscitó especial interés en todo el mundo, a finales de 1990, debido al enorme incremento de éstos y su especial vulnerabilidad. El representante del secretario general de las Naciones Unidas sobre la cuestión de los desplazados internos, Francis Deng, centró la atención en las necesidades, y para ello elaboró y público un conjunto de principios rectores para su protección y ayuda. ACNUR, Internally Displaced Persons: The Role of United Nations high Commissioner for Refugees, 2000.

77 El Programa de las Naciones Unidas para el Desarrollo actúa en una doble función: como principales funcionarios del PNUD en el país que se trate y como coordinadores residentes del sistema de las Naciones Unidas en ese país. En su calidad de coordinadores residentes tienen la función de coordinar la asistencia a las personas desplazadas internamente

78 El UNICEF ha intervenido en muchas situaciones de desplazamiento interno con esfuerzos encaminados a mejorar la vida de las mujeres y los niños mediante la prestación de servicios en salud, educación, nutrición y saneamiento.

79 El Programa Mundial de Alimentos lleva prestando ayuda alimentaria a desplazados internos hace 30 años. Aunque casi todas las operaciones tienen un carácter de socorro en sus primeras fases, muchas de ellas se transforman en proyectos de desarrollo, asimismo colaboran con otros organismos, ONG o donantes bilaterales. 
su vez está desarrollando proyectos en los sectores de prevención, protección y defensa de los derechos humanos, siendo éste el sector principal de su intervención. A ello se suman los de fortalecimiento institucional, integración y reconstrucción, educación y capacitación, salud y seguridad alimentaria. Las actividades que se realizan son las siguientes: promoción y difusión, atención psicosocial y educativa, apoyo a mujeres desplazadas, fortalecimiento institucional, desarrollo comunitario de asociaciones de desplazados e indígenas y apoyo de procesos de retorno y de reasentamiento, asistencia humanitaria y monitoreo de fronteras; ${ }^{80}$ éstas actividades benefician especialmente a la población en riesgo de desplazamiento, población desplazada y la población que se encuentra en procesos de reubicación y retorno.

La Cruz Roja también está presente, tiene un Comité Internacional con oficina en Bogotá, y 17 delegaciones en todo el país. Realiza contactos con todas las partes en conflicto para promover el respecto al derecho internacional humanitario y proporciona ayuda a las personas desplazadas por la violencia. ${ }^{81}$ Desde luego, de todas las instituciones que se ocupan del desplazamiento interno, la Cruz Roja es quien tiene el mandato más claro de ayudar y proteger a las víctimas en conflictos internos, quienes constituyen si no el número más numeroso, por lo menos el más complejo.

Y por último, un organismo que ha estado relacionado con el conflicto es la Unión Europea, ${ }^{82}$ en el marco convencional de la cooperación al desarrollo se enmarca dentro del Acuerdo Marco de Cooperación firmado en 1993 entre la UE y la Comunidad Andina, que se encuentra presente desde 1969; en principio se denominó "Pacto Andino". Dentro de éste se encuentran: Colombia, Bolivia, Ecuador, Perú y Venezuela. Fue

80 Informe del Grupo Temático de Desplazamiento (GTD), Estado de situación del desplazamiento de enero a junio de 2002, p. 40, http://www.col.ops-oms.org.

81 González Bustelo, Mabel, Desterrados. El desplazamiento forzado en Colombia, Médicos sin Fronteras, 2001, p. 44.

82 Se puede consultar la decisión de Chrenek Dusan, Policy Unit-Consejo de la Unión Europea, "Política de la Unión Europea respecto a Colombia", Las III Jornadas Abiertas a la Cooperación Internacional con Colombia, ¿Paz y Derechos Humanos?, Taula Catalana per la Pau i les Drets Humans a Colombia, Barcelona, 14-16 de abril de 2005. 
ratificado por Colombia en 1983 y por el Consejo de la UE por Decisión 98/278, de $1998 .{ }^{83}$

Los esfuerzos de la Unión Europea pretenden promover los derechos humanos en Colombia, todo ello sin dejar de hacer un seguimiento de la situación humanitaria, el buen gobierno, apoyando el esfuerzo gubernamental de reforzar el Estado de derecho en el país. Por medio de la Oficina Humanitaria de la Unión Europea (ECHO) se está tratando de incrementar su acción en cabeceras municipales de tamaño medio para evitar en la medida de lo posible la llegada en masa de desplazados a grandes ciudades, estabilizando la situación antes donde es más fácil la identificación de ésta población. A su vez, realiza talleres con las ONG para que unifiquen criterios en temas diversos. ${ }^{84}$

Los "laboratorios de paz" son el conjunto de proyectos más importantes de la Unión Europea en Colombia. Éstos intentan crear espacios de convivencia en medio del conflicto mediante la puesta en práctica de mecanismos innovadores, pero viables y eficaces, de resolución de conflictos, de respeto de los derechos humanos, y de reconstrucción del tejido social y de la economía. ${ }^{85}$ Esto se pretende conseguir por medio de activación de procesos de participación ciudadana y a su vez, el fortalecimiento de las institucionales locales para que éstas incidan en planos económicos, sociales, culturales y políticos.

Dentro del objetivo de apoyar la paz, el desarrollo económico y social, "los laboratorios de paz" constituyen el principal instrumento de la cooperación técnica y financiera de la comunidad y la necesidad de atacar las causas socioeconómicas del mismo. Uno de los problemas presentes y que ha recibido críticas desde algunos sectores, es porque la ayuda económica de la UE va directamente al gobierno, quien, a su vez, es el encargado de administrarla. Los programas no son independientes y no cuentan con la intervención de la población civil en el diseño y ejecución, sino que son incluidos dentro del Plan Nacional de Desarrollo.

Los laboratorios abarcan procesos sociales de participación, fortalecimiento institucional local y regional, que buscan generar transformaciones políticas, culturales, sociales y económicas para lograr una paz

83 Peco Yeste, Miguel et al., op. cit., nota 12, pp. 98 y 99.

84 González Bustelo, Mabel, op. cit., nota 81, p. 43.

85 Informe del CIP-FUHEM, La Unión Europea y Colombia en la Encrucijada, Madrid, Centro de Investigación para la Paz, 2006, pp. 8-13. 
duradera y mejores condiciones de vida para todos los habitantes. Con esto se busca la articulación de movimientos que surgen desde la base, permitiendo la reconstrucción del tejido social y la reapropiación de lo público por parte de la sociedad civil. La Comisión Europea pretende a través de los laboratorios de paz, trabajar en proyectos integrales que sean la expresión de procesos sociales participativos donde la reparación de los derechos humanos sea base en el desarrollo de la población y la recuperación del sentido de la ciudadanía, para que de esta manera se contribuya al logro de la paz. ${ }^{86}$

Sin embargo, a pesar de todos los esfuerzos que se han llevado en Colombia hasta la actualidad, la Unión Europea no ha podido tener una política coherente, su discurso se ha basado en conseguir una paz permanente y en la lucha antiterrorista; pero son muchos los factores ${ }^{87}$ que intervienen en el conflicto y dificultan la labor del Estado para mejorar la situación. Lo cual supone un desafío complicado para los organismos internacionales que intervienen en el país. ${ }^{88}$

\section{CONCLUSIONES}

En el Estado colombiano los diferentes actores del conflicto no respetan al derecho internacional humanitario, especialmente los principios de distinción, proporcionalidad, limitación e inmunidad de la población civil. Se ataca de manera indiscriminada a ésta, sometiéndola a todo tipo

86 http:/www.laboratoriodepaz.org.

87 Se sabe que el desplazamiento forzado es provocado por un sinnúmero de factores que lo convierten en una estrategia rentable en el marco del conflicto armado. Se menciona que la estrategia de desarraigo obedece a la disputa territorial por la concentración de la tierra con fines de mera especulación, y se habla del papel que en ello juegan los megaproyectos de inversión de interés continental en diferentes sectores, así como del rol que desempeña el Plan Colombia, los tratados de libre comercio y la estrategia de seguridad democrática del actual gobierno. Pues bien, todo eso hay que colocarlo sobre la mesa, si en verdad se quiere superar el estado de cosas inconstitucional declarado por la Corte Constitucional.

88 Los proyectos que se han llevado a cabo han tenido poco impacto por la escasez de recursos y por políticas contradictorias. Para que estos proyectos tengan éxito dentro de la sociedad colombiana, las ayudas deben orientarse al fortalecimiento de la democracia, a la protección de los derechos humanos y la reducción de la pobreza, a integrar a la sociedad dentro de los proyectos por desarrollar, y mediante el apoyo a la gobernabilidad y el cumplimiento de la ley. 
de agresiones. A pesar de que se encuentran tipificados en el Código Penal, éste no se hace efectivo ya que hasta la fecha no se ha castigado a los culpables por este tipo de violaciones a los derechos humanos. La protección hacia los civiles sólo se ha podido llevar a cabo a través de la acción de tutela ${ }^{89}$ presentada de forma individual o colectiva por algunas organizaciones de desplazados para la protección y garantía de los derechos constitucionales fundamentales.

La respuesta del Estado colombiano ante esta situación es fundamentalmente normativista y centrada en la creación de un cuerpo complejo de leyes con una brecha creciente en cuanto a su aplicación, debido a la insuficiencia de recursos de la administración. La Ley 387 no tiene una estructura cohesionada ni presupuesto para ponerla en práctica; existen diferentes instituciones nacionales implicadas como son las departamentales y las locales que difícilmente logran una coordinación.

El Estado se encuentra en la obligación de ayudar al retorno de los desplazados a sus hogares de manera voluntaria y segura. Asimismo, está obligado a buscar los medios de fortalecer los mecanismos judiciales para impedir la impunidad de quienes son los causantes de los desplazamientos en la población civil.

Al pensar que se está ante un problema de terrorismo y no de conflicto armado, hace que no se tomen en cuenta las causas reales que lo producen, y por tanto, se deja a un lado a la población civil sin ningún tipo de reparación y reconocimiento de sus derechos, creando con esto un clima de total impunidad. No debemos olvidar que las diversas causas del conflicto colombiano generaron un fenómeno de desplazamientos particulares los cuales requieren soluciones diferentes y no de manera general, como existe en la legislación actual.

En Colombia se presenta una serie de problemas estructurales que contribuyen al desplazamiento, en particular: la ausencia del Estado en diferentes regiones del país y el aumento de los grupos armados que han hecho de la violencia un factor funcional a sus intereses. Es necesaria la creación de una Comisión de la Verdad para la justicia y reparación de las víctimas del desplazamiento colombiano, quien a su vez puede pre-

89 Artículo 1o. y 2o. del Decreto 2591 de 1991. Acción de tutela. También existe la posibilidad de presentar una acción de cumplimiento para hacer efectivo una ley o actos administrativos. 
sentar una denuncia por la violación de los derechos humanos de las víctimas del desplazamiento forzado en Colombia.

La falta de disposición del Estado colombiano para administrar justicia, daría lugar al ejercicio de la competencia de la Corte Penal Internacional, fundamentalmente, a la existencia de situaciones de impunidad que vulneran el derecho a la justicia de las víctimas por las violaciones graves de los derechos humanos o del derecho internacional humanitario, como es el caso de los desplazados. Colombia es signataria del Estatuto de Roma y llevó a cabo enmiendas constitucionales que explícitamente autorizan su ratificación, por lo que no puede eludir la aplicación de la jurisdicción de la CPI a su situación. La jurisdicción de la Corte no es aplicable retroactivamente, y por lo tanto, sólo puede juzgar crímenes perpetrados después del 10 . de julio de 2002, lo cual limita su eficacia en el caso del conflicto colombiano, que tiene una existencia de más de 40 años. 